\title{
Effective model predictive instantaneous power control for a sensorless induction motor drive
}

\author{
Mahmoud A. Mossa* and Silverio Bolognani \\ Department of Industrial Engineering (DII), \\ University of Padova, \\ Via Gradenigo 6/a, Padova 35131, Italy \\ Email: mahmoudabdelwahabmossa.mohamed@studenti.unipd.it \\ Email: silverio.bolognani@dii.unipd.it \\ *Corresponding author
}

\begin{abstract}
This paper presents an effective sensorless model predictive instantaneous power control (MP IPC) technique for an induction motor (IM) drive. The proposed control method is considered as an alternative control approach for classic field-oriented control (FOC) and direct torque control (DTC) techniques, with merits of simple implementation and avoiding the usage of PI current controllers and pulse width modulation (PWM) for voltage control purposes. An effective sensorless approach for the purpose of speed and rotor position estimations is proposed, which utilises the predictive feature of the proposed MP IPC technique. Matlab simulation is firstly used to validate the effectiveness of the proposed control topology, and then a dSpace1104 prototyping control board is used to implement the approach experimentally. Obtained results confirm the feasibility of proposed control technique in achieving decoupled control of instantaneous active and reactive powers flow through the IM drive, which consequently accompanied with decoupled control of torque and flux.
\end{abstract}

Keywords: power control; linear extrapolation; induction motor drive; model predictive control; sensorless control.

Reference to this paper should be made as follows: Mossa, M.A. and Bolognani, S. (2018) 'Effective model predictive instantaneous power control for a sensorless induction motor drive', Int. J. Industrial Electronics and Drives, Vol. 4, No. 1, pp.44-55.

Biographical notes: Mahmoud A. Mossa graduated and received his Bachelor and Master's degrees in Electrical Engineering from Faculty of Engineering, Minia University - Egypt in 2008 and 2013, respectively. Since January 2010, he was working as an Assistant Lecturer at the Electrical Engineering Department at the same university. Since November 2014, he is doing his $\mathrm{PhD}$ research activities at the Department of Industrial Engineering in University of Padova in ITALY. His current researches are focused on developing effective control techniques for different topologies of induction machine drives based on model predictive control approaches.

Silverio Bolognani received his Laurea degree in Electrical Engineering from the University of Padova, Padova, Italy, in 1976. In the same year, he joined the Department of Electrical Engineering at that university. $\mathrm{He}$ is presently engaged in research on advanced control techniques for motor drives and motion control and design of ac electrical motors for variable-speed applications. He is the author of more than 200 papers on electrical machines and drives. He has been serving international conferences as a member of the Steering or Technical Committees. Currently, he is a senior member of IEEE and the Chairman of the IEEE North Italy IAS/IES/PELS Joint Chapter.

\section{Introduction}

In the year 1970s, the field-oriented control (FOC) was firstly introduced as a control solution for AC machines (Blaschke, 1971). The majority of the research was dedicated to induction motor (IM) that was considered as the horsepower in industry during this interval. The adjustable speed drives utilising FOC technique are then became widely used (Profumo et al., 1995; Kim and Sul, 1995; Profumo et al., 1994). After about 30 years, Noguchi and Takahashi (1984), Takahashi and Noguchi (1986) and Takahashi and Ohmori (1989), introduced the DTC of IM drives, which has the advantages of simple configuration, high dynamic performance and robustness.

The main drawbacks of FOC technique is that it requires performing co-ordinate transformations between reference frames (Tang et al., 2016; Espinoza et al., 2013; Mon et al., 2017), specifically between stationary and synchronous rotating frames, which increases the complexity of the system. In contrast, DTC can be applied in stationary reference frame; in addition, it is robust against machine parameters variation. 
However, for both control techniques FOC and DTC, the flux is one of the main two controlled variables, that is estimated using the voltage model of the IM equivalent circuit and consequently can be affected by parameters variation (Morey et al., 2016; Chacko et al., 2016; Bazzi et al., 2009; Bayoumi, 2014; Bayoumi and Soliman, 2008). In addition, the torque itself is still estimated in terms of the measured currents and estimated flux, thus by indirect way it can be affected by parameters variation.

Thus, to find a way to eliminate this effect, the torque and flux control is replaced with controlling the instantaneous power flow inside the IM. The concept of power control was applied to reactive power compensator applications many years ago (Akagi et al., 1984), but its application to electrical machine drives is still limited, some studies concerned with studying this control procedure and applying it to $\mathrm{AC}$ machines are presented as reported in (Lee and Blaabjerg, 2008; Jianbo et al., 2009). The instantaneous power control (IPC) method introduced in these previous studies combines some features from classic DTC and FOC techniques, but the utilisation of co-ordinate transformation and PI power controllers are still present. This in addition to the need for using a pulse width modulation (PWM) for voltage control purposes.

In order to avoid these gaps, an effective formulation of model predictive instantaneous power control (MP IPC) is introduced and investigated in this paper. The proposed MP IPC combines all the merits from FOC and DTC techniques while overcoming their shortages, this is clear from the absence of co-ordinate transformation, less dependency on machine parameters and avoiding the usage of PWM. In addition, to enhance the robustness of the control procedure, the control uses an effective sensorless technique that is based on the utilisation of prediction step within the proposed control approach, which proofed its effectiveness as reported in Mossa and Bolognani (2016a, 2016b). Moreover, the analytical approach for the proposed MP IPC enables the investigation of speed influence on the voltage vector selection process and on the overall performance of the active and reactive powers control. In particular, the usage of speed-dependent look-up tables used regularly in classic DTC control procedures can be investigated, and this can be a contribution for the paper.

\section{Mathematical model of IM}

In order to implement the proposed control principle, a discrete model of IM is used. Figure 1 shows the equivalent circuit of IM in which all quantities are space vectors in the stationary reference frame and rotor parameters are referred to stator side, the stationary reference frame is selected for simplifying the calculations and improving the system robustness as in this case there is no need to consider the losses caused by dynamics of the rotor i.e., (due to rotor rotating speed) for particular parameter calculations.
Figure 1 Equivalent circuit of IM in stationary reference frame

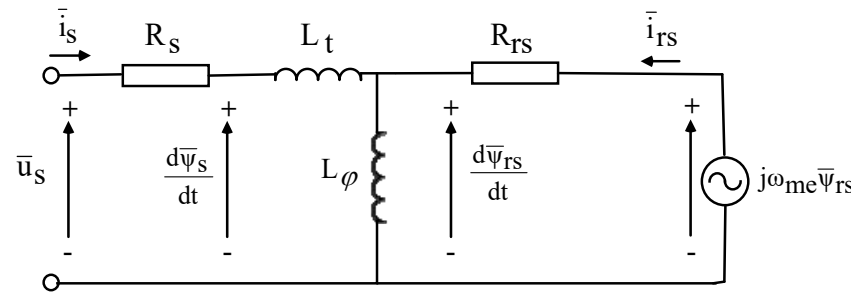

Equations that describe the voltage balance in the IM equivalent circuit at sampling instant $\mathrm{k}$ are as following:

$$
\begin{aligned}
& \left(\frac{\mathrm{d} \bar{\psi}_{\mathrm{s}}}{\mathrm{dt}}\right)_{\mathrm{k}}=\overline{\mathrm{u}}_{\mathrm{s}, \mathrm{k}}-\mathrm{R}_{\mathrm{s}} \overline{1}_{\mathrm{s}, \mathrm{k}} \\
& \left(\frac{\mathrm{d} \bar{\psi}_{\mathrm{rs}}}{\mathrm{dt}}\right)_{\mathrm{k}}=-\mathrm{R}_{\mathrm{rs}} \overline{1}_{\mathrm{rs}, \mathrm{k}}+\mathrm{j} \omega_{\mathrm{me}, \mathrm{k}} \bar{\psi}_{\mathrm{rs}, \mathrm{k}}
\end{aligned}
$$

where $\omega_{\mathrm{me}, \mathrm{k}}$ refers to the electrical angular speed and equals $\left(\mathrm{p} \omega_{\mathrm{m}, \mathrm{k}}\right)$, with $\mathrm{p}=$ pole pairs, and $\omega_{\mathrm{m}, \mathrm{k}}$ is the mechanical angular speed. In addition:

$$
\begin{aligned}
& \mathrm{R}_{\mathrm{rs}}=\mathrm{R}_{\mathrm{r}}\left(\frac{\mathrm{L}_{\mathrm{M}}}{\mathrm{L}_{\mathrm{r}}}\right)^{2} ; \quad \mathrm{L}_{\varphi}=\frac{\mathrm{L}_{\mathrm{M}}^{2}}{\mathrm{~L}_{\mathrm{r}}} ; \quad \mathrm{L}_{\mathrm{t}}=\mathrm{L}_{\mathrm{s}}-\frac{\mathrm{L}_{\mathrm{M}}^{2}}{\mathrm{~L}_{\mathrm{r}}} \text { and } \\
& \overline{1}_{\mathrm{rs}, \mathrm{k}}=\overline{1}_{\mathrm{r}, \mathrm{k}} \frac{\mathrm{L}_{\mathrm{r}}}{\mathrm{L}_{\mathrm{M}}} \quad \bar{\psi}_{\mathrm{rs}, \mathrm{k}}=\bar{\psi}_{\mathrm{r}, \mathrm{k}} \frac{\mathrm{L}_{\mathrm{M}}}{\mathrm{L}_{\mathrm{r}}} .
\end{aligned}
$$

in which $\mathrm{L}_{\mathrm{s}}, \mathrm{L}_{\mathrm{M}}, \mathrm{L}_{\mathrm{r}}$ are stator, mutual and rotor inductances of the motor.

Flux-current relations are expressed by

$$
\begin{aligned}
& \bar{\psi}_{\mathrm{s}, \mathrm{k}}=\left(\mathrm{L}_{\underline{\mathrm{t}}}+\mathrm{L}_{\varphi}\right) \overline{1}_{\mathrm{s}, \mathrm{k}}+\mathrm{L}_{\varphi} \overline{1}_{\mathrm{rs}, \mathrm{k}} \\
& \bar{\psi}_{\mathrm{rs}, \mathrm{k}}=\mathrm{L}_{\varphi}\left(\overline{1}_{\mathrm{s}, \mathrm{k}}+\overline{1}_{\mathrm{rs}, \mathrm{k}}\right)
\end{aligned}
$$

After some manipulations, equation (2) can be replaced with the following equation

$$
\begin{aligned}
\left(\frac{\mathrm{d} \overline{1}_{\mathrm{s}}}{\mathrm{dt}}\right)_{\mathrm{k}}= & \frac{1}{\mathrm{~L}_{\mathrm{t}}}\left[\overline{\mathrm{u}}_{\mathrm{s}, \mathrm{k}}-\left(\mathrm{R}_{\mathrm{s}}+\mathrm{R}_{\mathrm{rs}} \frac{\mathrm{L}_{\mathrm{t}}+\mathrm{L}_{\varphi}}{\mathrm{L}_{\varphi}}\right) \overline{1}_{\mathrm{s}, \mathrm{k}}\right. \\
& \left.+\frac{\mathrm{R}_{\mathrm{rs}}}{\mathrm{L}_{\varphi}} \bar{\psi}_{\mathrm{s}, \mathrm{k}}-\mathrm{j} \omega_{\mathrm{me}, \mathrm{k}}\left(\bar{\psi}_{\mathrm{s}, \mathrm{k}}-\mathrm{L}_{\mathrm{t}} \overline{1}_{\mathrm{s}, \mathrm{k}}\right)\right]
\end{aligned}
$$

Equations (1) and (5) construct the state model that describes the dynamic behaviour of the motor.

Motor torque can be then expressed by

$$
\mathrm{m}_{\mathrm{k}}=1.5 \mathrm{p} \operatorname{Im}\left(\check{\psi}_{\mathrm{s}, \mathrm{k}} \overline{1}_{\mathrm{s}, \mathrm{k}}\right)=1.5 \mathrm{p} \frac{\mathrm{L}_{\mathrm{M}}}{\mathrm{L}_{\mathrm{r}}} \operatorname{Im}\left(\check{\psi}_{\mathrm{r}, \mathrm{k}} \overline{1}_{\mathrm{s}, \mathrm{k}}\right)
$$

where accent $\checkmark$ is for complex conjugate. From equation (6) the derivative for the torque results as

$$
\begin{aligned}
\left(\frac{\mathrm{dm}}{\mathrm{dt}}\right)_{\mathrm{k}} & =1.5 \mathrm{p} \operatorname{Im}\left(\frac{\mathrm{d} \check{\Psi}_{\mathrm{s}, \mathrm{k}}}{\mathrm{dt}} \overline{1}_{\mathrm{s}, \mathrm{k}}+\check{\Psi}_{\mathrm{s}, \mathrm{k}} \frac{\mathrm{d} \overline{\mathrm{s}}_{\mathrm{s}, \mathrm{k}}}{\mathrm{dt}}\right) \\
& =1.5 \mathrm{p} \frac{\mathrm{L} \mathrm{M}}{\mathrm{L}_{\mathrm{r}}}\left(\frac{\mathrm{d} \check{\psi}_{\mathrm{rs}, \mathrm{k}}}{\mathrm{dt}} \overline{1}_{\mathrm{s}, \mathrm{k}}+\check{\Psi}_{\mathrm{rs}, \mathrm{k}} \frac{\mathrm{d} \overline{1}_{\mathrm{s}, \mathrm{k}}}{\mathrm{dt}}\right)
\end{aligned}
$$


where derivatives in equation (7) are given by equations (1), (2) and (5) in term of spatial voltage vector.

\section{Proposed (MP IPC) control approach}

The proposed MP IPC algorithm consists of two main stages; the first one is concerned with the derivation of power reference commands, while the second is dedicated for describing the implementation procedure of proposed technique. Both stages are treated and analysed in the following subsections.

In principle, the complex apparent power of the machine represented in space vector notation can be given by

$$
\mathrm{S}_{\mathrm{k}}=1.5\left(\overline{\mathrm{u}}_{\mathrm{s}, \mathrm{k}} \check{1}_{\mathrm{s}, \mathrm{k}}\right)
$$

From equation (8), the instantaneous active and reactive powers are calculated as follows:

$$
\begin{aligned}
& \mathrm{P}_{\mathrm{s}, \mathrm{k}}=1.5 \operatorname{Re}\left(\overline{\mathrm{u}}_{\mathrm{s}, \mathrm{k}} \breve{\mathrm{l}}_{\mathrm{s}, \mathrm{k}}\right) \\
& \mathrm{Q}_{\mathrm{s}, \mathrm{k}}=1.5 \operatorname{Im}\left(\overline{\mathrm{u}}_{\mathrm{s}, \mathrm{k}} \check{\mathrm{i}}_{\mathrm{s}, \mathrm{k}}\right)
\end{aligned}
$$

The instantaneous active power $\mathrm{P}_{\mathrm{s}, \mathrm{k}}$ denotes to the power being dissipated in the slip modified rotor resistance of the machine $\left(\mathrm{R}_{\mathrm{r}} / \mathrm{slip}\right.$ ) (this is if the losses in iron and losses due to stator resistance are ignored), plus the power stored in the airgap. While, the instantaneous reactive power denotes to the instantaneous rate of change in flux vector's magnitude and its acceleration.

If $\mathrm{P}_{\mathrm{s}, \mathrm{k}}$ is controlled, and the flux in the machine is kept constant, then this approximately controls the developed torque of the machine as

$$
\mathrm{P}_{\mathrm{s}, \mathrm{k}}=\mathrm{m}_{\mathrm{k}} \omega_{\mathrm{m}, \mathrm{k}}
$$

where $\omega_{\mathrm{m}, \mathrm{k}}=\left(\frac{\omega_{\mathrm{me}, \mathrm{k}}}{\mathrm{p}}\right)$ is the mechanical angular speed. Similarly, the reactive power controls the flux in the machine.

\subsection{Power reference generation stage}

The simplest reference to be derived is the active power one $\mathrm{P}_{\mathrm{s}, \mathrm{k}}^{*}$, since this reference is directly related to the desired torque to be developed by the machine.

It is clear that $P_{s, k}^{*}$ can be calculated by

$$
\mathrm{P}_{\mathrm{s}, \mathrm{k}}^{*}=\mathrm{m}_{\mathrm{k}}^{*} \omega_{\mathrm{m}, \mathrm{k}}
$$

where $\mathrm{m}_{\mathrm{k}}^{*}$ is the reference torque.

Equation (12) works to some extent, but it can generates values of active power which may be insufficient to develop and generate the reference torque $\mathrm{m}_{\mathrm{k}}^{*}$. This is due to that not all input active power to the machine participates in the construction of output power. This is because of losing some power in stator resistance and iron losses in addition to the power dissipated in the rotor resistance, which in terms depends on the slip of the machine.
If it is assumed that the power lost in stator resistance and that goes as iron losses can be neglected, the power loss due to rotor resistance cannot be avoided.

Figure 2 Power flow inside IM (see online version for colours)

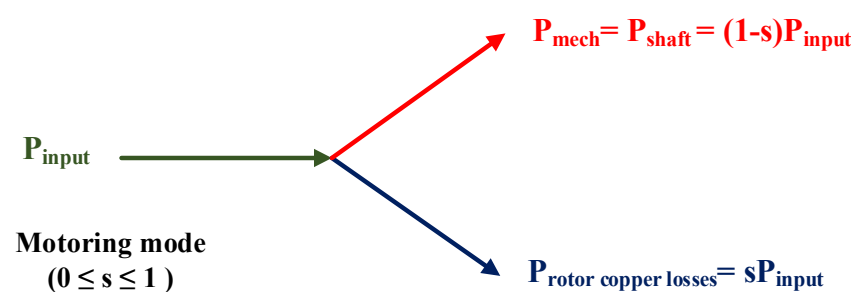

The power flow inside the machine can be represented as shown in Figure 2 through which it can be noticed that the input active power is divided into two parts, the first dissipates into the rotor resistance while the second is consumed as output mechanical power.

Thus, to make the output mechanical power equal to the desired shaft power, the part of power lost in the rotor resistance should be compensated, and to do this the machine slip should be identified.

According to above hypothesis and assuming that the slip is known, the active power reference to be utilised can be represented by:

$$
\mathrm{P}_{\mathrm{s}, \mathrm{k}}^{*}=\frac{\mathrm{P}_{\text {shaft }}}{1-\text { slip }}=\frac{\mathrm{m}_{\mathrm{k}}^{*} \omega_{\mathrm{m}, \mathrm{k}}}{1-\text { slip }}
$$

where $P_{\text {shaft }}$ is the desired shaft mechanical power.

To develop a formulation for the slip to be used for the compensation purpose, the derivation of reactive power reference value is utilised for this purpose. Figure 3 shows the space vector diagram of voltages, currents and fluxes for the induction machine.

Figure 3 Space vector representation for IPC (see online version for colours)

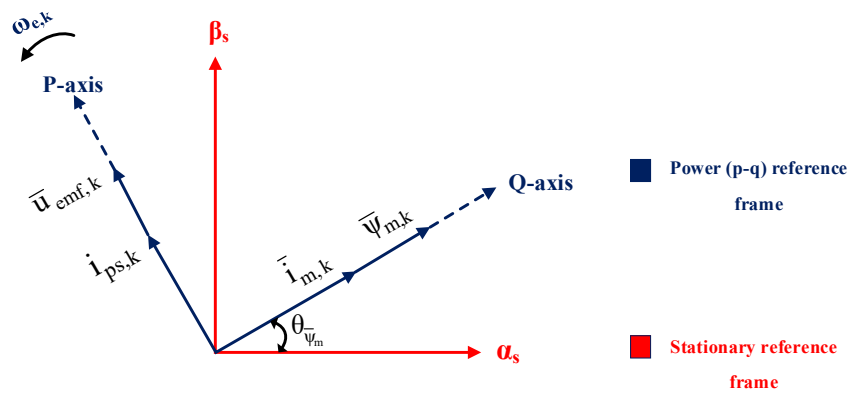

From Figure 3, it can be noticed that the reactive power $\mathrm{Q}_{\mathrm{s}, \mathrm{k}}$ can be calculated via the multiplication of the back emf voltage $\overline{\mathrm{u}}_{\mathrm{emf}, \mathrm{k}}$ in one axis of the machine and the magnetising current $\overline{1}_{\mathrm{m}, \mathrm{k}}$ in the other axis, thus

$$
\left|\mathrm{Q}_{\mathrm{s}, \mathrm{k}}\right|=\overline{\mathrm{i}}_{\mathrm{m}, \mathrm{k}} \overline{\mathrm{u}}_{\mathrm{emf}, \mathrm{k}}=\overline{\mathrm{i}}_{\mathrm{m}, \mathrm{k}} \omega_{\mathrm{e}, \mathrm{k}} \bar{\psi}_{\mathrm{m}, \mathrm{k}}
$$

where $\omega_{\mathrm{e}, \mathrm{k}}=\omega_{\mathrm{me}, \mathrm{k}}+\omega_{\mathrm{slip}, \mathrm{k}}$ is the applied electrical frequency and $\bar{\psi}_{\mathrm{m}, \mathrm{k}}$ is the magnetising airgap flux.

From equation (14), the reference angular slip $\omega_{\text {slip,k}}^{*}$ can be calculated by 


$$
\omega_{\mathrm{slip}, \mathrm{k}}^{*}=\frac{\left|-\mathrm{Q}_{\mathrm{s}, \mathrm{k}}^{*}\right|}{\overline{\mathbf{1}}_{\mathrm{m}, \mathrm{k}}^{*} \bar{\psi}_{\mathrm{m}, \mathrm{k}}^{*}}-\omega_{\mathrm{me}, \mathrm{k}}
$$

It is worth to notice that the relation between the magnetising flux and magnetising current can be given by

$$
\bar{\psi}_{\mathrm{m}, \mathrm{k}}=\mathrm{L}_{\mathrm{M}} K * \overline{1}_{\mathrm{m}, \mathrm{k}}
$$

The negative sign in equation (15) results from the sign of $\mathrm{Q}_{\mathrm{s}, \mathrm{k}}^{*}$ that will be derived later. by

From equations (15) and (16), the slip can be computed

$$
\operatorname{slip}=\frac{\omega_{\text {slip }, \mathrm{k}}}{\omega_{\mathrm{me}, \mathrm{k}}+\omega_{\text {slip }, \mathrm{k}}}=1+\frac{\omega_{\mathrm{me}, \mathrm{k}}}{\mathrm{Q}_{\mathrm{s}, \mathrm{k}}^{*} \mathrm{~L}_{\mathrm{M}}\left(\bar{\psi}_{\mathrm{m}, \mathrm{k}}^{*}\right)^{2}}
$$

Then, from equation (17) and substituting in equation (13), the reference of active power can be derived as:

$$
P_{s, k}^{*}=-\frac{\mathrm{m}_{\mathrm{k}}^{*} \omega_{\mathrm{m}, \mathrm{k}} \mathrm{Q}_{\mathrm{s}, \mathrm{k}}^{*} \mathrm{~L}_{\mathrm{M}}}{\omega_{\mathrm{me}, \mathrm{k}}\left(\bar{\psi}_{\mathrm{m}, \mathrm{k}}^{*}\right)^{2}}=-\frac{\mathrm{L}_{\mathrm{M}} \mathrm{Q}_{\mathrm{s}, \mathrm{k}}^{*} \mathrm{~m}_{\mathrm{k}}^{*}}{\mathrm{p}\left(\bar{\psi}_{\mathrm{m}, \mathrm{k}}^{*}\right)^{2}}
$$

From equation (14), it can be noticed that the reactive power is dependent on the angular slip frequency $\omega_{\text {slip,k }}$ of the machine, which in terms is related to the developed torque of the machine.

The developed torque can be given after applying FOC principle as:

$$
\mathrm{m}_{\mathrm{k}}=1.5 \mathrm{p} \frac{\mathrm{L}_{\mathrm{M}}}{\mathrm{L}_{\mathrm{r}}}\left(\bar{\psi}_{\mathrm{m}, \mathrm{k}} \cong \psi_{\mathrm{qm}, \mathrm{k}}\right) \mathrm{i}_{\mathrm{ps}, \mathrm{k}}
$$

where $\left(\psi_{\mathrm{pm}, \mathrm{k}}\right.$ and $\left.\psi_{\mathrm{qm}, \mathrm{k}}\right)$ and $\left(\mathrm{i}_{\mathrm{ps}, \mathrm{k}}\right.$ and $\left.\mathrm{i}_{\mathrm{qs}, \mathrm{k}}\right)$ are the magnetising airgap flux and stator current components in the synchronously rotating $(\mathrm{p}-\mathrm{q})$ frame as illustrated in Figure 3.

Using the same FOC principle, the angular slip frequency can be given by

$$
\omega_{\text {slip }, \mathrm{k}}=\frac{\mathrm{i}_{\mathrm{ps}, \mathrm{k}} \mathrm{L}_{\mathrm{M}}}{\mathrm{T}_{\mathrm{r}}\left|\bar{\psi}_{\mathrm{m}, \mathrm{k}} \cong \psi_{q m, k}\right|}
$$

where $T_{r}=L_{r} / R_{r}$ is the rotor time constant.

From equation (19) the p-axis component of stator current is given as:

$$
\mathrm{i}_{\mathrm{ps}, \mathrm{k}}=\frac{\mathrm{m}_{\mathrm{k}}}{1.5 \mathrm{p} \frac{\mathrm{L}_{\mathrm{M}}}{\mathrm{L}_{\mathrm{r}}}\left|\bar{\psi}_{\mathrm{m}, \mathrm{k}} \cong \psi_{\mathrm{qm}, \mathrm{k}}\right|}
$$

From equation (21) and by substituting in equation (20) and assuming that the rotor leakage inductance is very small compared with the rotor inductance $\left(\mathrm{L}_{\mathrm{r}} \cong \mathrm{L}_{\mathrm{M}}\right)$, this results in:

$$
\omega_{\mathrm{slip}, \mathrm{k}}=\frac{\mathrm{m}_{\mathrm{k}} \mathrm{L}_{\mathrm{M}}}{1.5 \mathrm{p}\left|\bar{\psi}_{\mathrm{m}, \mathrm{k}} \cong \psi_{\mathrm{qm}, \mathrm{k}}\right|^{2} \mathrm{~T}_{\mathrm{r}}}
$$

Then, by substituting from equation (22) into equation (14), the reactive power reference to be used is given by

$$
\mathrm{Q}_{\mathrm{s}, \mathrm{k}}^{*}=-\left[\frac{\left|\bar{\psi}_{\mathrm{m}, \mathrm{k}} \cong \psi_{\mathrm{qm}, \mathrm{k}}\right|^{2}}{\mathrm{~L}_{\mathrm{M}}} \omega_{\mathrm{me}, \mathrm{k}}+\frac{\mathrm{m}_{\mathrm{k}}^{*}}{1.5 \mathrm{pT} \mathrm{T}_{\mathrm{r}}}\right]
$$

It is worth to notice that the negative sign $(-)$ in equation (23) is used to give the right sign for inductive reactive power, as the induction machine is considered as an inductive load.

\subsection{Power prediction stage}

From equations (9) and (10), the derivatives of active and reactive powers can be computed as:

$$
\begin{aligned}
& \frac{\mathrm{dP}_{\mathrm{s}, \mathrm{k}}}{\mathrm{dt}}=1.5 \operatorname{Re}\left[\overline{\mathrm{u}}_{\mathrm{s}, \mathrm{k}} \frac{\mathrm{d \check {1 } _ { \mathrm { s } , \mathrm { k } }}}{\mathrm{dt}}+\check{\mathrm{i}}_{\mathrm{s}, \mathrm{k}} \frac{\mathrm{d} \overline{\mathrm{u}}_{\mathrm{s}, \mathrm{k}}}{\mathrm{dt}}\right] \\
& \frac{\mathrm{dQ} \mathrm{s}, \mathrm{k}}{\mathrm{dt}}=1.5 \operatorname{Im}\left[\overline{\mathrm{u}}_{\mathrm{s}, \mathrm{k}} \frac{\mathrm{d} \check{\mathrm{i}}_{\mathrm{s}, \mathrm{k}}}{\mathrm{dt}}+\check{1}_{\mathrm{s}, \mathrm{k}} \frac{\mathrm{d} \overline{\mathrm{u}}_{\mathrm{s}, \mathrm{k}}}{\mathrm{dt}}\right]
\end{aligned}
$$

Equation (5) gives the derivative for the stator current, while the stator voltage derivative can be calculated by

$$
\frac{\mathrm{du}}{\mathrm{s}, \mathrm{k}}=\frac{\overline{\mathrm{u}}_{\mathrm{s}, \mathrm{k}}-\overline{\mathrm{u}}_{\mathrm{s}, \mathrm{k}-1}}{\mathrm{dt}}
$$

Consequently, from equations (9), (10), (24) and (25), the values of active and reactive powers can be predicted at sampling instant $(\mathrm{k}+1) \mathrm{T}_{\mathrm{s}}$ as follows:

$$
\begin{aligned}
& \tilde{\mathrm{P}}_{\mathrm{s}, \mathrm{k}+1}=\mathrm{P}_{\mathrm{s}, \mathrm{k}}+\frac{\mathrm{dP}_{\mathrm{s}, \mathrm{k}}}{\mathrm{dt}} \\
& \tilde{Q}_{\mathrm{s}, \mathrm{k}+1}=\mathrm{Q}_{\mathrm{s}, \mathrm{k}}+\frac{\mathrm{dQ}_{\mathrm{s}, \mathrm{k}}}{\mathrm{dt}}
\end{aligned}
$$

\section{Implementation procedure}

After the derivation of active and reactive powers reference values using equations (18) and (23), and after the calculation of the predicted values using equations (27) and (28), the next step is to utilise a cost function that will guide the control system to select the most suitable (optimal) voltage vector to be applied to the motor's terminals, in case of that the absolute value of predicted error exceeds its maximum limit $\mathrm{E}_{\max }$ as can be seen in Figure 4, which illustrates the action taken by the control for two different cases according to the instantaneous value of the predicted error.

The error vector can be represented at instant $\mathrm{kT}_{\mathrm{s}}$ as:

$$
\bar{e}_{k}=\frac{P_{s, k}^{*}-P_{s, k}}{S_{n}}+j w_{f} \frac{Q_{s, k}^{*}-Q_{s, k}}{S_{n}}=e_{P_{s, k}}+j w_{f} e_{Q_{s, k}}
$$

where $S_{n}$ is the rated apparent power of induction machine, and $\mathrm{w}_{\mathrm{f}}$ is a weighting factor that is used to give a weight for the reactive power respecting to the active power's value. 
Figure 4 Conditions for the existence of IPC in the error plane, (a) right action (b) wrong action (see online version for colours)

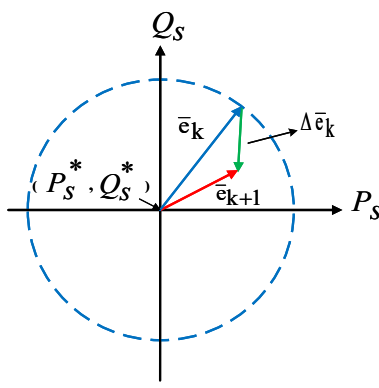

(a)

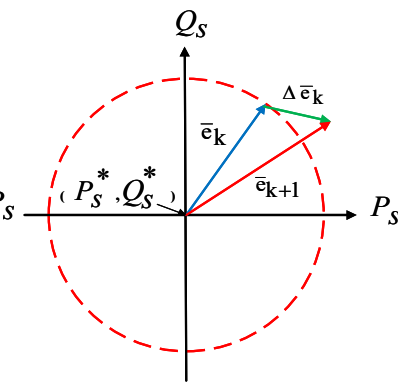

(b)
The target of the control is to maintain at any sampling time the vector $\left|e_{k}\right|$ very close to zero, by applying a suitable voltage vector to the motor terminals. In other words, the following inequality must be satisfied:

$$
\left|\overline{\mathrm{e}}_{\mathrm{k}}\right|=\sqrt{\left(\mathrm{e}_{\mathrm{P}_{\mathrm{s}, \mathrm{k}}}\right)^{2}+\mathrm{w}_{\mathrm{f}}^{2}\left(\mathrm{e}_{\mathrm{Q}_{\mathrm{s}, \mathrm{k}}}\right)^{2}} \leq \mathrm{E}_{\max }
$$

From equation (30) it can be noticed that, when the error exceeds $E_{\max }$, the proper way to bring it again below, is to select the voltage vector which causes a negative variation to the error, and to check this, equation (30) is differentiated with respect to the time and from the results of derivation a convergence condition is derived, this condition will be responsible for selecting the optimal voltage vectors, and it is derived at instant $(\mathrm{k}+1) \mathrm{T}_{\mathrm{s}}$ as follows:

$$
\tilde{\mathrm{C}}_{\mathrm{k}+1}^{\mathrm{i}}=\left[\tilde{\mathrm{e}}_{\mathrm{P}_{\mathrm{s}, \mathrm{k}+1}}\left(\frac{\mathrm{d} \tilde{\mathrm{P}}_{\mathrm{s}}}{\mathrm{dt}}\right)_{\mathrm{k}+1}+\mathrm{w}_{\mathrm{f}} \tilde{\mathrm{e}} \mathrm{Q}_{\mathrm{s}, \mathrm{k}+1}\left(\frac{\mathrm{d} \tilde{\mathrm{Q}}_{\mathrm{s}}}{\mathrm{dt}}\right)_{\mathrm{k}+1}\right]^{\mathrm{i}}
$$

\section{Sensorless approach}

While the system is running in the sampling interval between $\mathrm{kT}_{\mathrm{s}}$ and $(\mathrm{k}+1) \mathrm{T}_{\mathrm{s}}$ (the current interval), let's consider the sampling interval between $(\mathrm{k}-1) \mathrm{T}_{\mathrm{s}}$ and $\mathrm{kT}_{\mathrm{s}}$ (the last ended interval). Both instants $(\mathrm{k}-1) \mathrm{T}_{\mathrm{s}}$ and $\mathrm{kT}_{\mathrm{s}}$ related to the completed interval as shown in Figure 5.

Figure 5 Control algorithm sampling intervals

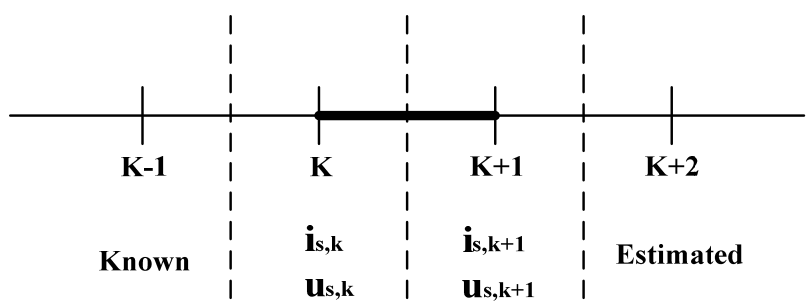

The stator current at instant $\mathrm{kT}_{\mathrm{s}}$ can be given by

$$
\begin{aligned}
\overline{1}_{\mathrm{s}, \mathrm{k}} & =\overline{1}_{\mathrm{s}, \mathrm{k}-1}+\mathrm{T}_{\mathrm{s}}\left(\frac{\mathrm{d} \overline{1}_{\mathrm{s}}}{\mathrm{dt}}\right)_{\mathrm{k}-1} \\
& =\overline{1}_{\mathrm{s}, \mathrm{k}-1}+\mathrm{T}_{\mathrm{s}}\left(\frac{\mathrm{d} \overline{1}_{\mathrm{s}}}{\mathrm{dt}}\right)_{\mathrm{k}-1}^{(\mathrm{u})}+\mathrm{T}_{\mathrm{s}}\left(\frac{\mathrm{d} \overline{1}_{\mathrm{s}}}{\mathrm{dt}}\right)_{\mathrm{k}-1}^{(\omega)}
\end{aligned}
$$

where

$$
\begin{aligned}
& \left(\frac{\mathrm{d} \overline{1}_{\mathrm{s}}}{\mathrm{dt}}\right)_{\mathrm{k}-1}^{(\mathrm{u})} \\
& =\frac{1}{\mathrm{~L}_{\mathrm{t}}}\left[\overline{\mathrm{u}}_{\mathrm{s}, \mathrm{k}-1}-\left(\mathrm{R}_{\mathrm{s}}+\mathrm{R}_{\mathrm{rs}} \frac{\mathrm{L}_{\mathrm{t}}+\mathrm{L}_{\varphi}}{\mathrm{L}_{\varphi}}\right) \overline{1}_{\mathrm{s}, \mathrm{k}-1}+\frac{\mathrm{R}_{\mathrm{rs}}}{\mathrm{L}_{\varphi}} \bar{\psi}_{\mathrm{s}, \mathrm{k}-1}\right]
\end{aligned}
$$

and

$$
\left(\frac{\mathrm{d} \overline{\mathbf{1}}_{\mathrm{s}}}{\mathrm{dt}}\right)_{\mathrm{k}-1}^{(\mathrm{u})}=-\frac{1}{\mathrm{~L}_{\mathrm{t}}}\left[\mathrm{j} \omega_{\mathrm{me}, \mathrm{k}-1}\left(\bar{\psi}_{\mathrm{s}, \mathrm{k}-1}-\mathrm{L}_{\mathrm{t}} \overline{\mathbf{1}}_{\mathrm{s}, \mathrm{k}-1}\right)\right]
$$

After $\mathrm{kT}_{\mathrm{s}}$, the ability to measure $\overline{1}_{\mathrm{s}, \mathrm{k}}$ and $\overline{1}_{\mathrm{s}, \mathrm{k}-1}$ is available. Consequently, equation (32) can be rewritten by

$$
\overline{1}_{\mathrm{s}, \mathrm{k}}-\overline{\mathbf{1}}_{\mathrm{s}, \mathrm{k}-1}-\mathrm{T}_{\mathrm{s}}\left(\frac{\mathrm{d} \overline{\mathrm{s}}_{\mathrm{s}}}{\mathrm{dt}}\right)_{\mathrm{k}-1}^{(\mathrm{u})}=\mathrm{T}_{\mathrm{s}}\left(\frac{\mathrm{d} \overline{1}_{\mathrm{s}}}{\mathrm{dt}}\right)_{\mathrm{k}-1}^{(\omega)}
$$

From equation (34), the speed sample at instant $(\mathrm{k}-1) \mathrm{T}_{\mathrm{s}}$ is given by

$$
\omega_{\mathrm{me}, \mathrm{k}-1}=j \mathrm{~L}_{\mathrm{t}} \frac{\overline{1}_{\mathrm{s}, \mathrm{k}}-\overline{\mathbf{1}}_{\mathrm{s}, \mathrm{k}-1}-\mathrm{T}_{\mathrm{s}}\left(\frac{\mathrm{d} \overline{\mathrm{s}}_{\mathrm{s}}}{\mathrm{dt}}\right)_{\mathrm{k}-1}^{(\mathrm{u})}}{\mathrm{T}_{\mathrm{s}}\left(\bar{\psi}_{\mathrm{s}, \mathrm{k}-1}-\mathrm{L}_{\mathrm{t}} \overline{1}_{\mathrm{s}, \mathrm{k}-1}\right)}
$$

which concludes to a real number that can be evaluated as:

$$
=-\mathrm{L}_{\mathrm{t}} \operatorname{Im}\left[\frac{\left(\overline{1}_{\mathrm{s}, \mathrm{k}}-\overline{\mathrm{1}}_{\mathrm{s}, \overline{\mathrm{k}}-1}-\mathrm{T}_{\mathrm{s}}\left(\frac{\mathrm{d} \overline{1}_{\mathrm{s}}}{\mathrm{dt}}\right)_{\mathrm{k}-1}^{(\mathrm{u})}\right) \operatorname{conj}\left(\bar{\psi}_{\mathrm{s}, \mathrm{k}-1}-\mathrm{L}_{\mathrm{t}} \overline{1}_{\mathrm{s}, \mathrm{k}-1}\right)}{\mathrm{T}_{\mathrm{s}}\left(\bar{\psi}_{\mathrm{s}, \mathrm{k}-1}-\mathrm{L}_{\mathrm{t}} \overline{1}_{\mathrm{s}, \mathrm{k}-1}\right) \operatorname{conj}\left(\bar{\psi}_{\mathrm{s}, \mathrm{k}-1}-\mathrm{L}_{\mathrm{t}} \overline{1}_{\mathrm{s}, \mathrm{k}-1}\right)}\right]
$$

All quantities in equations (36) and (37) are measured or are computed starting from measurements.

Now, in order to predict quantities at $(\mathrm{k}+1) \mathrm{T}_{\mathrm{s}}, \omega_{\mathrm{me}, \mathrm{k}}$ is required, but it is not yet obtainable (known). The suitable way to estimate it via assuming the same acceleration from interval $(\mathrm{k}-2) \mathrm{T}_{\mathrm{s}}$ to $(\mathrm{k}-1) \mathrm{T}_{\mathrm{s}}$, which can be represented as:

$$
\alpha=\frac{\left(\omega_{\mathrm{me}, \mathrm{k}-1}-\omega_{\mathrm{me}, \mathrm{k}-2}\right)}{\mathrm{T}_{\mathrm{s}}}
$$

Then, the speed at instant $\mathrm{kT}_{\mathrm{s}}$ can be evaluated by

$$
\omega_{\mathrm{me}, \mathrm{k}}=\omega_{\mathrm{me}, \mathrm{k}-1}+\alpha \mathrm{T}_{\mathrm{s}}=2 \omega_{\mathrm{me}, \mathrm{k}-1}-\omega_{\mathrm{me}, \mathrm{k}-2}
$$

Now by applying a linear extrapolation of the speed values starting from the last two estimated samples $(\mathrm{k}-2) \mathrm{T}_{\mathrm{s}}$ and $(\mathrm{k}-1) \mathrm{T}_{\mathrm{s}}$; thus $\omega_{\mathrm{me}, \mathrm{k}}$ can be obtained and then used for prediction purpose.

\section{Analysis of speed effect on the performance of proposed MP IPC}

As mentioned in previous sections, the effect of speed sample $\omega_{\mathrm{me}, \mathrm{k}}$ within the proposed MP IPC is varying according to the implementation step; this can be described as follows. 


\subsection{In prediction stage}

The speed is required in this step as the derivatives of stator current contains a speed dependent part as given by equation (5), and consequently both derivatives of active and reactive powers that are used for prediction needs the speed sample.

\subsection{In voltage selection stage}

The proposed MP IPC control approach selects the most suitable vector among the base voltage vectors delivered by the inverter that minimises the cost function given by equation (31) which can be rewritten as:

$$
\begin{aligned}
\tilde{\mathrm{C}}_{\mathrm{k}+1}^{i}= & {\left[\left(\tilde{\mathrm{P}}_{\mathrm{s}, \mathrm{k}+1}^{*}-\tilde{P}_{\mathrm{s}, \mathrm{k}+1}\right)\left(\frac{\mathrm{d} \tilde{\mathrm{P}}_{\mathrm{s}}}{\mathrm{dt}}\right)_{\mathrm{k}+1}\right.} \\
& \left.+\mathrm{w}_{\mathrm{f}}\left(\mathrm{Q}_{\mathrm{s}, \mathrm{k}+1}^{*}-\tilde{\mathrm{Q}}_{\mathrm{s}, \mathrm{k}+1}\right)\left(\frac{\mathrm{d} \tilde{\mathrm{Q}}_{\mathrm{s}}}{\mathrm{dt}}\right)_{\mathrm{k}+1}\right]^{\mathrm{i}}
\end{aligned}
$$

In which the active power derivative at instant $(\mathrm{k}+1)^{\text {th }}$ can be rewritten as

$$
\begin{aligned}
& \left(\frac{\mathrm{dP}}{\mathrm{dt}}\right)_{\mathrm{k}+1}=1.5 \operatorname{Re}\left[\overline{\mathrm{u}}_{\mathrm{s}, \mathrm{k}+1} \frac{1}{\mathrm{~L}_{\mathrm{t}}}\left[\overline{\mathrm{u}}_{\mathrm{s}, \mathrm{k}+1}-\mathrm{R}_{\mathrm{s}, \mathrm{k}+1}+\frac{\mathrm{R}_{\mathrm{rs}}}{\mathrm{L} \varphi} \bar{\psi}_{\mathrm{s}, \mathrm{k}+1}\right]\right. \\
& \left.+\check{1}_{\mathrm{s}, \mathrm{k}+1} \frac{\mathrm{d} \overline{\mathrm{u}}_{\mathrm{s}, \mathrm{k}+1}}{\mathrm{dt}}\right]
\end{aligned}
$$

where $\mathrm{R}=\mathrm{R}_{\mathrm{s}}+\mathrm{R}_{\mathrm{rs}} \frac{\mathrm{L}_{\mathrm{t}}+\mathrm{L}_{\varphi}}{\mathrm{L}_{\varphi}}$.

It can be realised from equation (41) that the active power derivative does not depend on the speed sample $\omega_{\mathrm{me}, \mathrm{k}+1}$.

While the derivative of reactive power can be given by

$$
\begin{aligned}
& \left(\frac{\mathrm{dQ}}{\mathrm{dt}}\right)_{\mathrm{k}+1} \\
& =1.5 \operatorname{Im}\left[\overline{\mathrm{u}}_{\mathrm{s}, \mathrm{k}+1}\left(\left(\frac{\mathrm{d} \overline{\mathbf{1}}_{\mathrm{s}}}{\mathrm{dt}}\right)_{\mathrm{k}+1}^{(\mathrm{u})}+\left(\frac{\mathrm{d} \overline{\mathrm{s}}_{\mathrm{s}}}{\mathrm{dt}}\right)_{\mathrm{k}+1}^{(\omega)}\right)\right] \\
& =1.5 \operatorname{Im}\left[\overline{\mathrm{u}}_{\mathrm{s}, \mathrm{k}+1}\left(\frac{1}{\mathrm{~L}_{\mathrm{t}}}\left[\mathrm{j} \omega_{\mathrm{me}, \mathrm{k} 1}\left(\bar{\psi}_{\mathrm{s}, \mathrm{k}+1}-\mathrm{L}_{\mathrm{t}} \overline{1}_{\mathrm{s}, \mathrm{k}+1}\right)\right]\right)\right. \\
& \left.-\mathrm{ji}_{\beta \mathrm{s}, \mathrm{k}+1} \frac{\mathrm{d} \overline{\mathrm{u}}_{\mathrm{s}, \mathrm{k}+1}}{\mathrm{dt}}\right]
\end{aligned}
$$

It can be noticed from equation (42), that it has two components, one that depends only on the voltage and free of speed sample, while the other is given as a function of the speed sample, the two parts can then be rewritten by:

$$
\mathrm{A}\left(\overline{\mathrm{u}}_{\mathrm{s}, \mathrm{k}+1}\right)=1.5 \operatorname{Im}\left[-\mathrm{ji}_{\beta \mathrm{s}+1} \frac{\mathrm{d} \overline{\mathrm{u}}_{\mathrm{s}, \mathrm{k}+1}}{\mathrm{dt}}\right]
$$

and

$$
\begin{aligned}
& B\left(\omega_{\mathrm{me}, \mathrm{k}+1}\right) \\
& =1.5 \operatorname{Im}\left[\overline{\mathrm{u}}_{\mathrm{s}, \mathrm{k}+1}\left(-\frac{1}{\mathrm{~L}_{\mathrm{t}}}\left[\mathrm{j} \omega_{\mathrm{me}, \mathrm{k}+1}\left(\bar{\psi}_{\mathrm{s}, \mathrm{k}+1}-\mathrm{L}_{\mathrm{t}} \overline{1}_{\mathrm{s}, \mathrm{k}+1}\right)\right]\right)\right]
\end{aligned}
$$

From equations (40), (41), (42.a) and (42.b), the convergence condition tends to be as following:

$$
\tilde{\mathrm{e}}_{\mathrm{P}_{\mathrm{s}, \mathrm{k}+1}}\left(\frac{\mathrm{d} \tilde{\mathrm{P}}_{\mathrm{s}}}{\mathrm{dt}}\right)_{\mathrm{k}+1}>-\left(\tilde{\mathrm{e}}_{\mathrm{Q}_{\mathrm{s}, \mathrm{k}+1}}\left(\mathrm{~A}\left(\overline{\mathrm{u}}_{\mathrm{s}, \mathrm{k}+1}\right)+\mathrm{B}\left(\omega_{\mathrm{me}, \mathrm{k}+1}\right)\right)\right)
$$

From equation (43), it can be deduced that, this condition can be achieved via applying more than one voltage vector, but the optimum voltage vector that will be selected is the first one that minimises equation (40) or maximises the left side of equation (43). Maximisation of the left side does not depend on the speed but only on the applied voltage vector at this instant, and thus the speed has no effect on the voltage vector selection procedure.

The procedure of voltage vector selection can be summarised in sequential steps as follows:

Step 1 Measuring of input stator voltage $\overline{\mathrm{u}}_{\mathrm{s}, \mathrm{k}}$ and current $\overline{1}_{\mathrm{s}, \mathrm{k}}$, and estimation of speed sample $\omega_{\mathrm{me}, \mathrm{k}}$ using the sensorless procedure previously presented in Section 5.

Step 2 Calculation of instantaneous values of active and reactive powers in terms of stator voltage and stator current.

Step 3 Prediction of active and reactive powers for all possible voltage vectors $(i=0 \ldots 7)$.

Step 4 Checking the predicted values of active and reactive powers in the cost function given by equation (31).

Step 5 The switching states correspond to the minimum value of the cost function are selected and then applied in the next control cycle to actuate the inverter.

The overall proposed control scheme is therefore that shown in Figure 6. The three phase two level voltage source inverter (VSI) is represented by a Zero-Order Hold ( $\mathrm{ZOH})$ block that is used for converting the discrete time signals to continuous time signals needed by the drive. A sample and hold $(\mathrm{S} / \mathrm{H})$ block is referring to the sampling (capturing) of a continuously varying signal (i.e., stator current) and holds (freezes) its value at a constant level for a specified minimum period in order to achieve an accurate measurement. Speed loop and prediction block are both utilising the estimated speed; it can be noticed that there is no existence for PWM used regularly with FOC for voltage control purposes. 
Figure 6 Complete system configuration for the proposed MP IPC approach (see online version for colours)

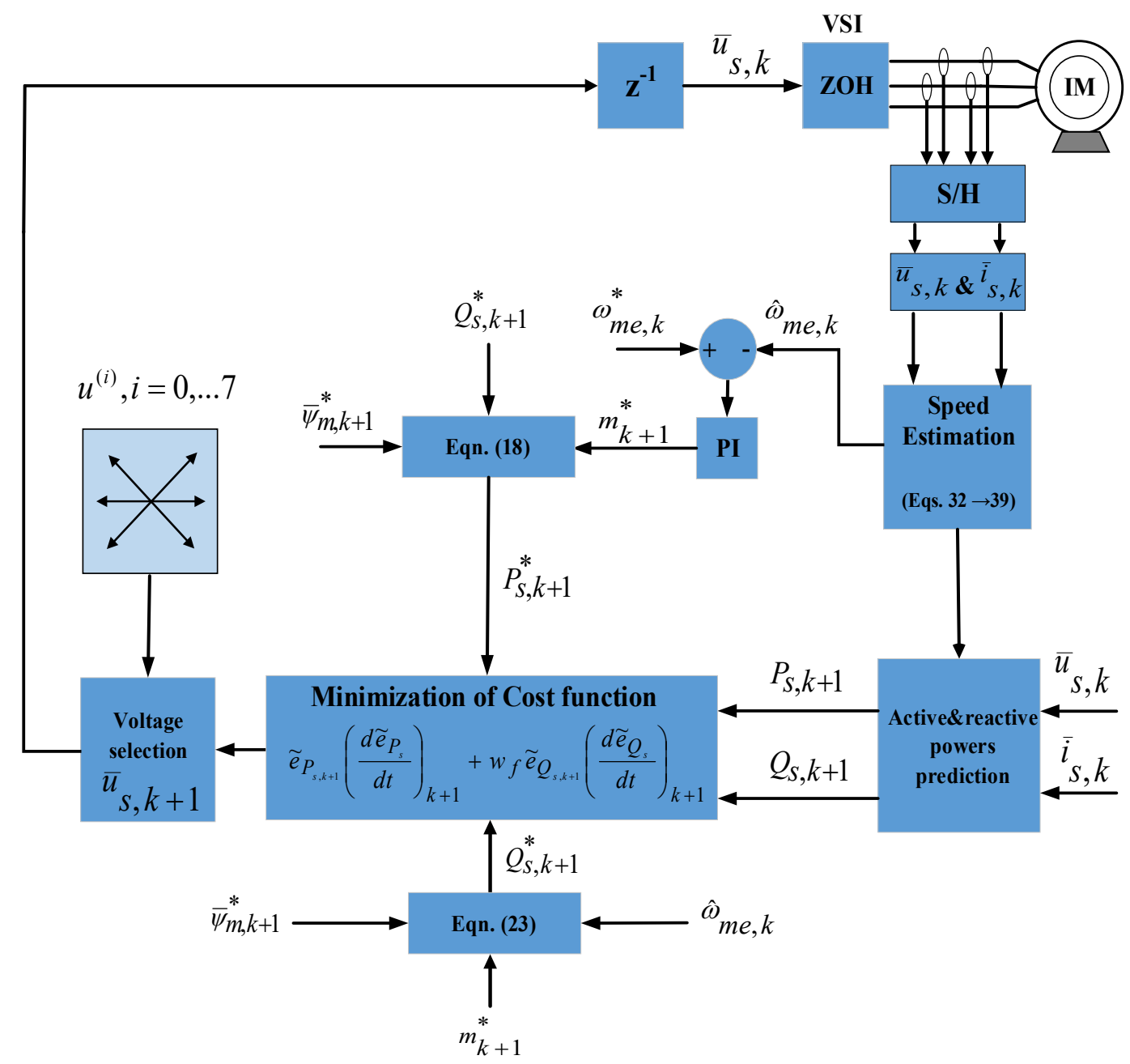

Figure 7 Speed, torque and magnetising flux, (a) rotational speed (RPM) (b) electromagnetic torque (Nm) (c) magnetising flux (Wb) (see online version for colours)

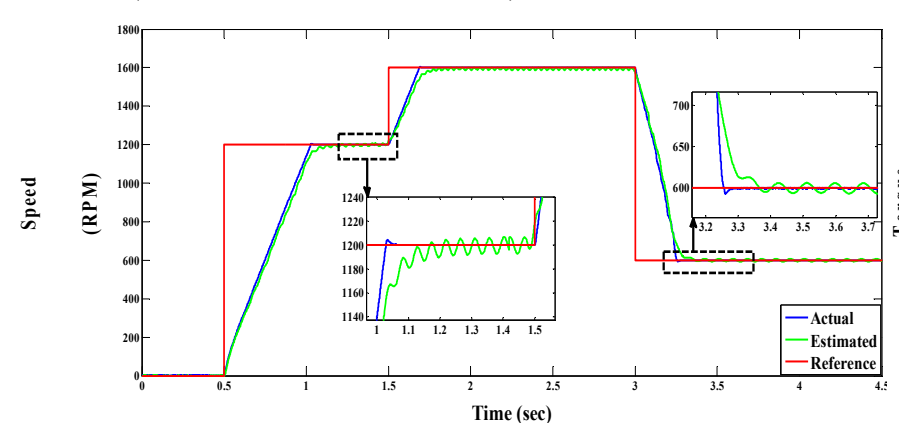

(a)

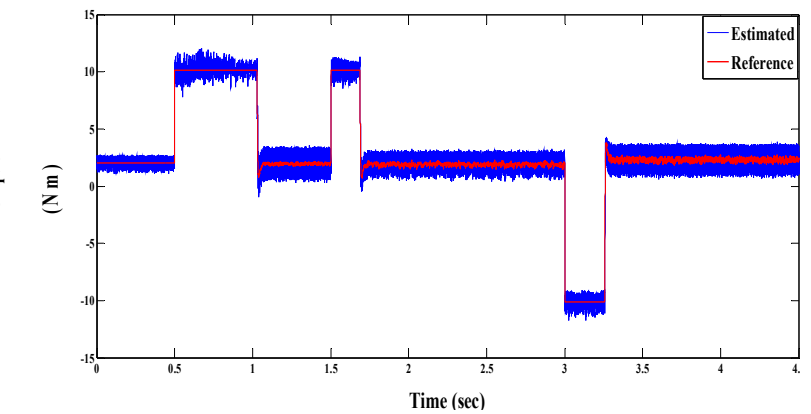

(b)

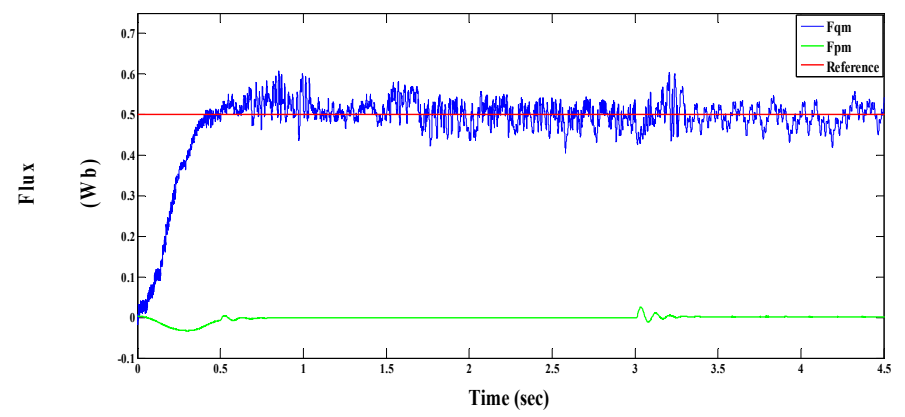

(c) 
Figure 8 Active and reactive powers (see online version for colours)
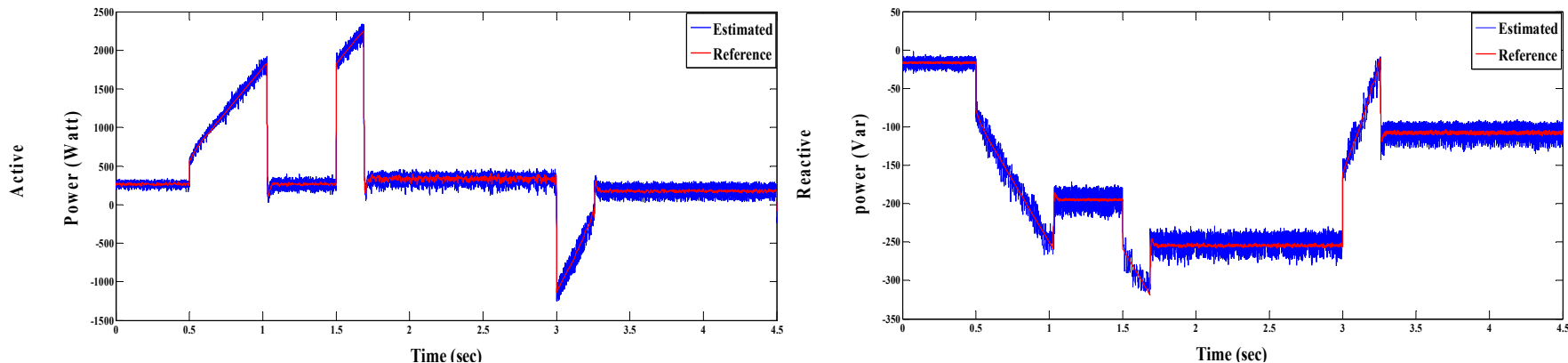

Figure 9 Control response for change in absolute error (see online version for colours)
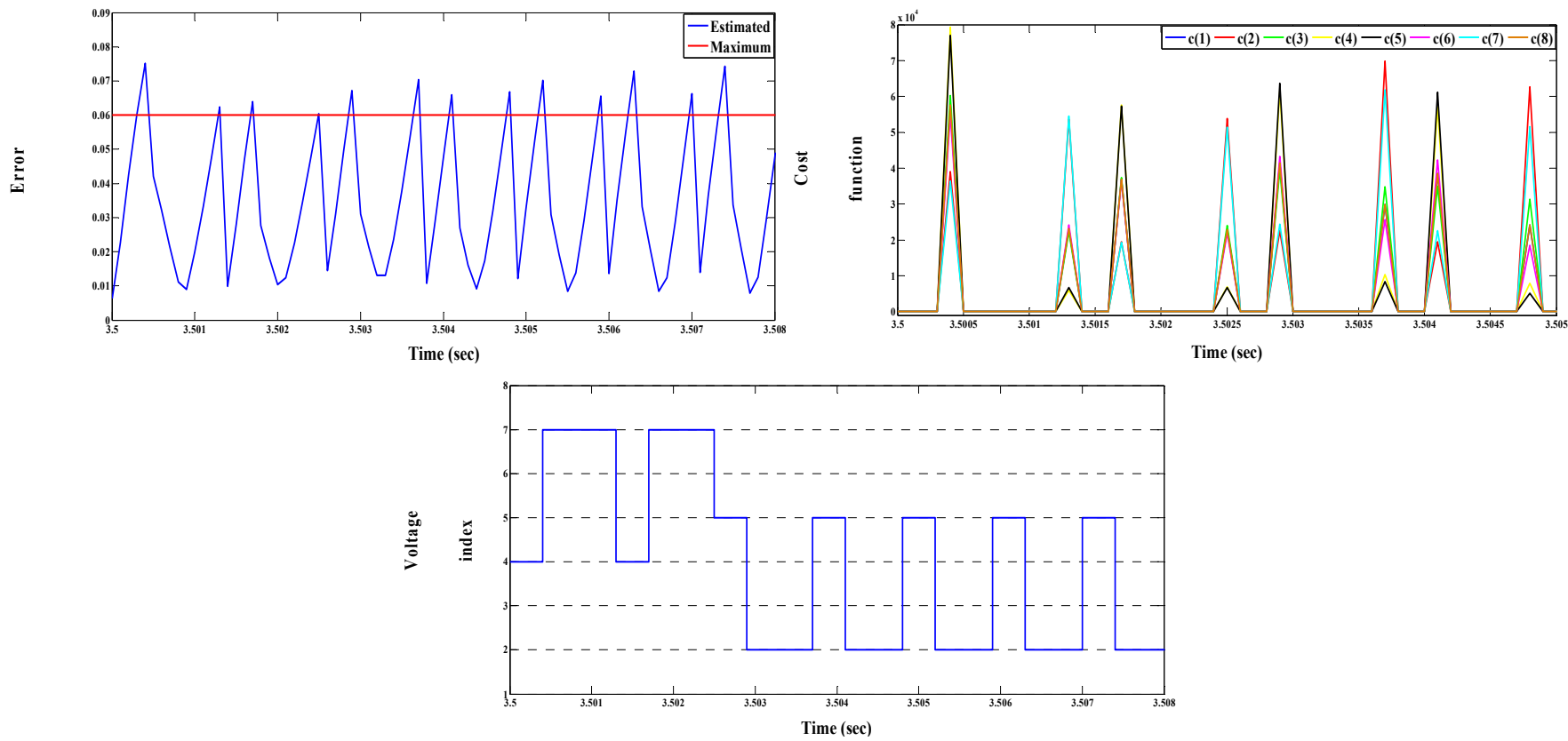

Figure 10 Rotor position (see online version for colours)

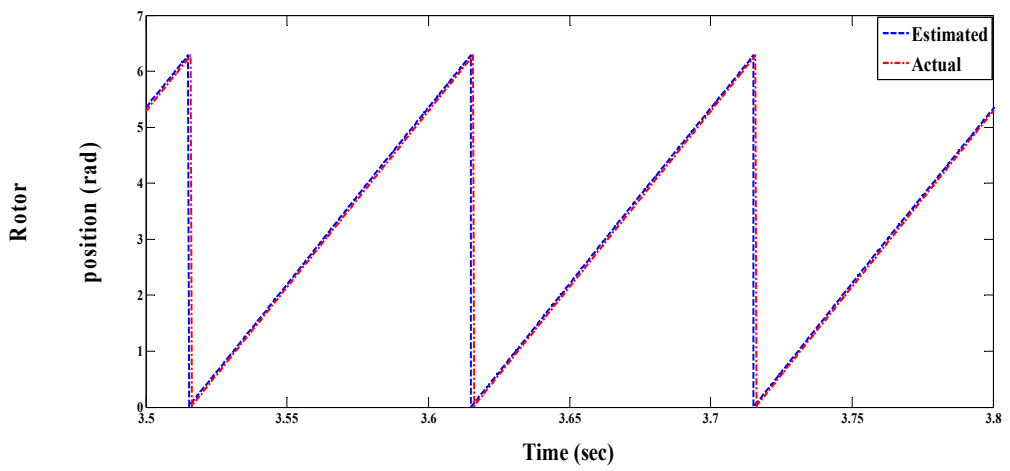

\section{Simulation results}

Matlab/Simulink software is firstly used to validate the effectiveness of proposed MP IPC, the tests are carried out for a speed range of $(0 \rightarrow 1,200 \rightarrow 1.600 \rightarrow 600 \mathrm{RPM})$ at times of $(0 \rightarrow 0.5 \rightarrow 1.5 \rightarrow 3 \mathrm{sec})$, aload torque of two $\mathrm{Nm}$ is applied at starting. The reference value for the magnetising flux $\psi_{\mathrm{m}, \mathrm{k}}^{*}$ is kept at $0.5 \mathrm{~Wb}$, while the maximum error limit is held to 0.06 . Obtained results confirm the feasibility of the control procedure; this can be noticed through Figures 7(a), 7(b) and 7(c) that give information about the speed, torque and magnetising flux, respectively. Figure 7(a) illustrates the actual and estimated speed, which are precisely matched and which consequently assure the validity of proposed sensorless approach. The obtained magnetising flux profile shown in Figure 7(b) confirm the validity of proposed control to achieve decoupling between the two components of the flux. Figure 8 shows the active and reactive powers profiles in which their estimated values follow precisely the imposed reference values. Figure 9 illustrates a detailed overview about the control response at 
each instant of variation in the error's value. Figure 10 shows the rotor position profile from which the effectiveness of the sensorless approach is also confirmed. Parameters of the IM and control system are given in Table 1 in Appendix.

\section{Experimental results}

The drive performance is validated experimentally using a fast control prototyping dSpace1104 board, test is carried out for a command speed change of $(1,200 \rightarrow 1,600 \rightarrow$ $600 \mathrm{RPM})$ at times of $(0 \rightarrow 1 \rightarrow 2.5 \mathrm{sec})$, the reference value for the magnetising flux is kept at $0.5 \mathrm{~Wb}$, while a two $\mathrm{Nm}$ load torque is applied at starting. The value of Emax that is used for limiting switching frequency is held to 0.06 as the same one used in simulation test. Complete flow diagram for the procedure used for selecting the optimal voltage vectors can be shown in Figure 12. The test bench layout is shown through Figure 11, which consists of an IM with a wound rotor type with its stator terminals connected to the terminals of a voltage source - two level inverter, while its rotor's terminals are short-circuited. The dSpace connector panel is used for transferring the control commands from the PC to VSI and then to the motor, a load torque controller is used to set the value of the motor's load. Over all dynamic performance for the IM drive is excellent and proves the feasibility of the proposed MP IPC technique, this is confirmed through the obtained results shown in Figures 13 and 14.

Figure 11 Teat bench layout (see online version for colours)

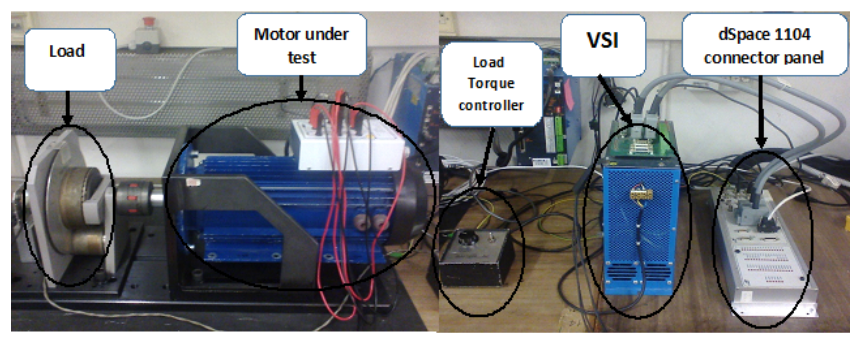

Figure 13 illustrates the dynamic performance for IM drive, the actual and estimated speeds are giving high matching rate that validates the effectiveness of sensorless scheme, while a decoupled control is achieved between magnetising flux components. In addition, the calculated values of active and reactive powers exhibit precise tracking for their commands. The developed torque of the motor is sustaining the value of the load torque during the speed changes. Figure 14 gives a detailed view of the action taken by the control system for each instant change in the error's value. Moreover, through Figure 14, it can be noticed that there is high coincidence between the actual and estimated rotor position, which consequently assure the proper performance of sensorless approach.

Figure 12 Procedure of implementation (see online version for colours)

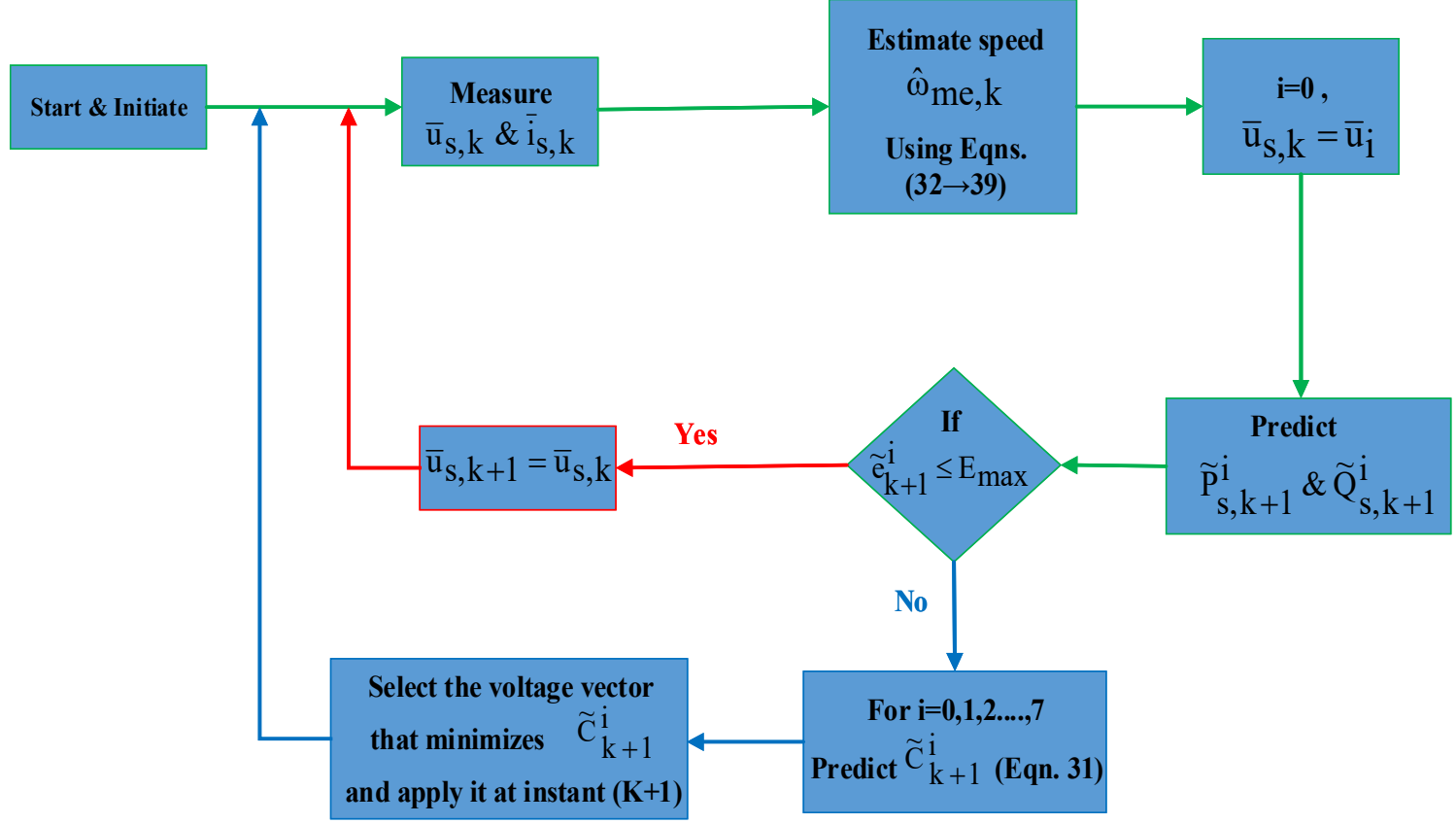


Figure 13 Dynamic behaviour for IM drive (experimental) (see online version for colours)
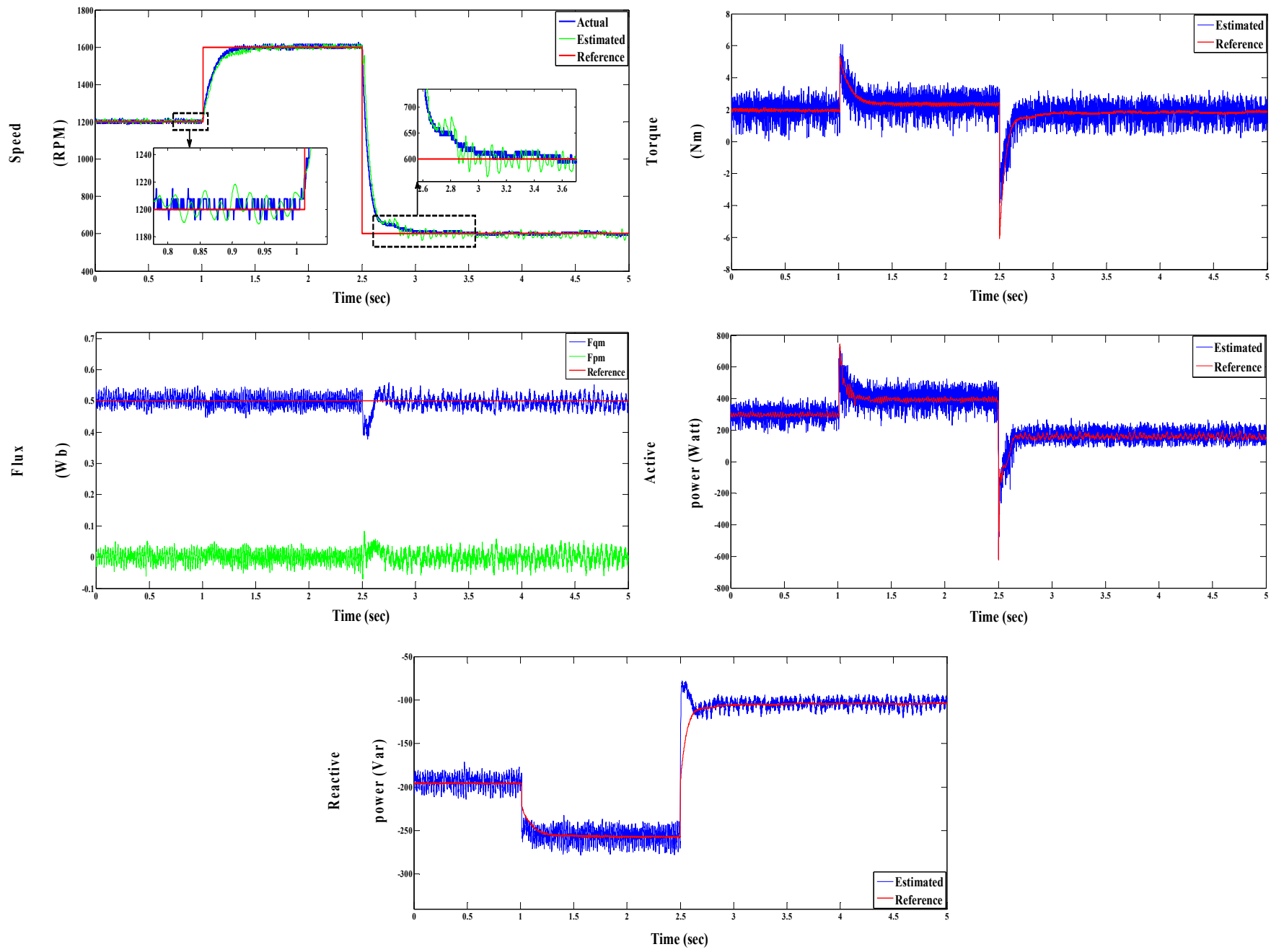

Figure 14 Control response and rotor position (see online version for colours)
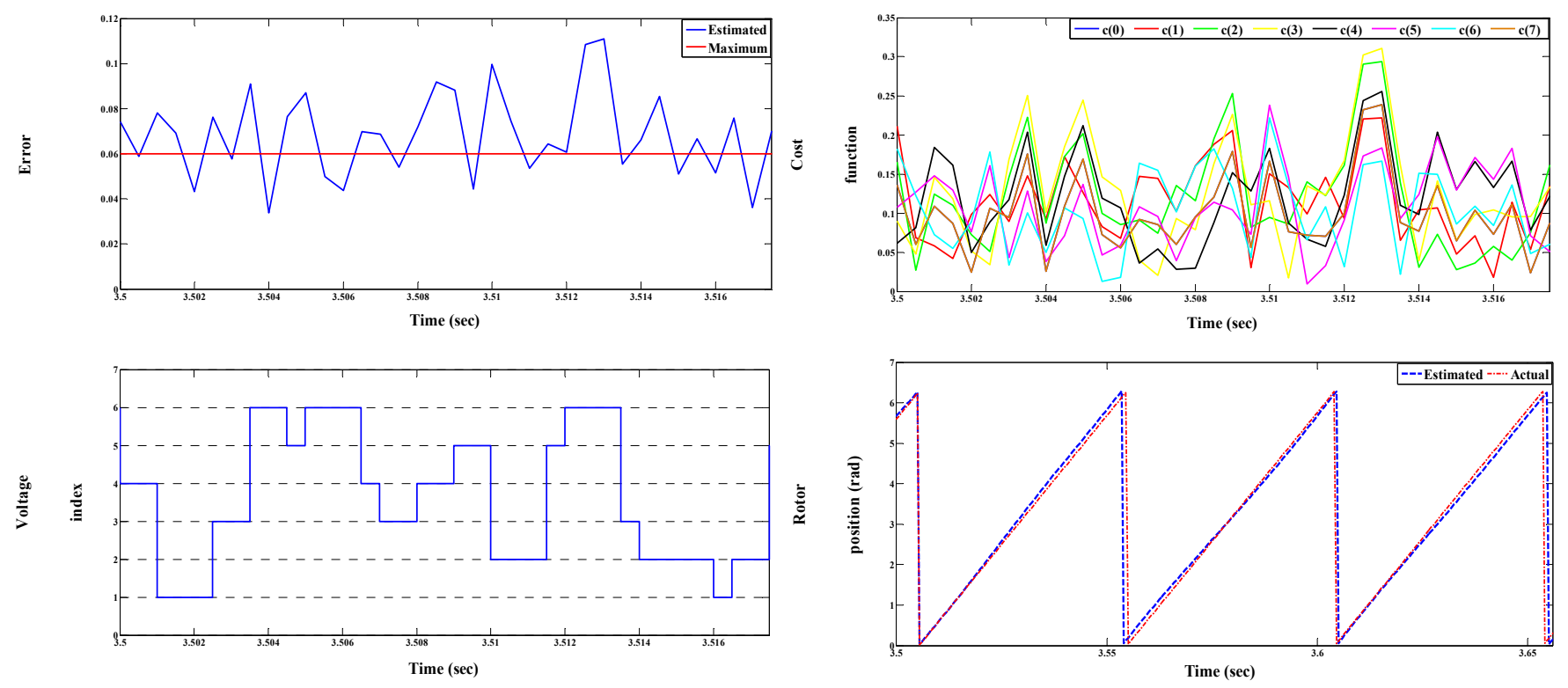


\section{Conclusions}

The paper has proposed an effective MP IPC for an IM drive. The proposed control topology is considered as an alternative control solution for classic FOC and DTC control techniques. An innovative sensorless speed estimation technique utilising the predictive nature of proposed MP IPC is presented. Overall dynamic performance of the proposed control scheme is excellent. Matlab/Simulation is firstly used for validating the effectiveness of the new formulation, and then experimental verification has been carried out utilising a dSpace1104 control board. Decoupled control of instantaneous active and reactive powers is achieved, which consequently accompanied with controlling the torque and flux of IM. A detailed analysis for the speed impacts on the overall performance of the proposed control procedure is introduced that gives a way for well understanding the basic operation of proposed control technique, when and why it works well.

\section{References}

Akagi, H., Kanazawa, Y. and Nabae, A. (1984) 'Instantaneous reactive power compensators comprising switching devices without energy storage components', IEEE Transactions on Industry Applications, Vol. IA-20, No. 3, pp.625-630.

Bayoumi, E.H.E (2014) 'Stator resistance estimator for direct torque control of permanent magnet synchronous motor drive systems using multi-resolution analysis wavelet', International Journal of Industrial Electronics and Drives, Vol. 1, No. 3, pp.191-201.

Bayoumi, E.H.E. and Soliman, H.M. (2008) 'A particle swarm optimization-based deadbeat on-line speed control for sensorless induction motor drives', Electromotion Scientific Journal, Vol. 15, No. 3, pp.141-153.

Bazzi, A.M., Friedl, A.P., Choi, S. and Krein, P.T. (2009) 'Comparison of induction motor drives for electric vehicle applications: dynamic performance and parameter sensitivity analyses', IEEE International Electric Machines and Drives Conference, Miami, FL, pp.639-646.

Blaschke, F. (1971) 'A new method for the structural decoupling of A.C. induction machines', Conf Rec. IFAC, Duesseldorf, Germany, pp.1-15.

Chacko, S., Bhende, C.N., Jain, S. and Nema, R.K. (2016) 'PSO based online tuning of PI controller for estimation of rotor resistance of indirect vector controlled induction motor drive', International Conference on Electrical, Electronics, and Optimization Techniques (ICEEOT), Chennai, pp.4606-4611.

Espinoza, D.R., Campos, D.U., Bossio, G., Barcenas, E., Hernandez, J.E. and Lugo, L.F. (2013) 'Fault diagnosis scheme for open-circuit faults in field-oriented control induction motor drives', IET Power Electronics, Vol. 6, No. 5, pp.869-877.
Jianbo, C., Yuwen, H., Wenxin, H., Yong, Li, Jianfei, Y. and Mingjin, W. (2009) 'Direct active and reactive power control of PMSM', IEEE 6th International Power Electronics and Motion Control Conference, Wuhan, pp.1808-1812.

Kim, S.H. and Sul, S.K. (1995) 'Maximum torque control of an induction machine in the field weakening region', IEEE Trans. Industry Applications, Vol. 31, No. 4, pp.784-794.

Lee, K. and Blaabjerg, F. (2008) 'Simple power control for sensorless induction motor drives fed by a matrix converter', IEEE Trans. Energy Conversion, Vol. 23, No. 3, pp.781-788.

Mon, D.L., Jin, T., Ekemb, G. and Bitjoka, L. (2017) 'Decoupling network of field-oriented control in variable-frequency drives', IEEE Transactions on Industrial Electronics, Vol. 64, No. 7, pp.5746-5750.

Morey, M.S., Virulkar, V.B. and Dhomane, G.A. (2016) 'MRAC based online stator resistance and rotor time constant estimation scheme in sensorless field oriented controlled induction motor drives', International Conference on Electrical, Electronics, and Optimization Techniques (ICEEOT), Chennai, pp.3422-3427.

Mossa, M.A. and Bolognani, S. (2016a) 'Effective model predictive direct torque control for an induction motor drive', IEEE International Symposium on Power Electronics, Electrical Drives, Automation and Motion (SPEEDAM), Anacapri, pp.746-754.

Mossa, M.A. and Bolognani, S. (2016b) 'Effective sensorless direct torque control for an induction motor drive with reduced ripple contents', IEEE International Conference on Power Electronics, Drives and Energy Systems (PEDES), Trivandrum, pp.1-6.

Noguchi, T. and Takahashi, I. (1984) 'Quick torque response control of an induction motor based on a new concept', IEEJ Tech. Meeting Rotating Mach., Vol. RM84-76, pp.61-70, in Japanese.

Profumo, F., DeDoncker, R., Ferraris, P. and Pastorelli, M. (1995) 'Comparison of universal field oriented (UFO) controllers in different reference frames', IEEE Trans. Power Electronics, Vol. 10, No. 2, pp.205-213.

Profumo, F., Griva, G., Moreira, J., Pastorelli, M. and Doncker, R.D. (1994) 'Universal field oriented controller based on air gap flux sensing via third harmonic stator voltage', IEEE Trans. Industry Applications, Vol. 30, No. 2, pp.448-455.

Takahashi, I. and Noguchi, T. (1986) 'A new quick response and high efficiency control strategy of an induction machine', IEEE Trans. Industry Applications, Vol. 22, No. 5, pp.820-827.

Takahashi, I. and Ohmori, Y. (1989) 'High-performance direct torque control of an induction motor', IEEE Trans. Industry Applications, Vol. 25, No. 2, pp.257-264.

Tang, Q., Ge, X. and Liu, Y.C. (2016) 'Performance analysis of two different SVM-based field-oriented control schemes for eight-switch three-phase inverter-fed induction motor drives', IEEE 8th International Power Electronics and Motion Control Conference (IPEMC-ECCE Asia), Hefei, pp.3374-3378. 


\section{Appendix}

Table 1 Parameters and data specifications of (IM)

\begin{tabular}{lc}
\hline Parameters & Value \\
\hline Rated power & $3.0 \mathrm{KW}$ \\
Poles pairs & 2 \\
$\mathrm{R}_{\mathrm{s}}$ & $1.50 \Omega$ \\
$\mathrm{L}_{\mathrm{s}}$ & $0.1785 \mathrm{H}$ \\
$\mathrm{R}_{\mathrm{r}}$ & $0.85 \Omega$ \\
$\mathrm{L}_{\mathrm{r}}$ & $0.18451 \mathrm{H}$ \\
$\mathrm{L}_{\mathrm{M}}$ & $0.17447 \mathrm{H}$ \\
$\mathrm{Rated} \mathrm{torque}$ & $10.125 \mathrm{Nm}$ \\
$\mathrm{K}_{\mathrm{p}}$ (speed controller) & 14.26 \\
$\mathrm{~K}_{\mathrm{I}}$ (speed controller) & 1,263 \\
$\mathrm{w}_{\mathrm{f}}$ (weighting factor) & 1.15 \\
\hline
\end{tabular}

